\title{
BALANCED SCORECARD APLICADO EM LABORATÓRIOS DE ANÁLISES CLÍNICAS
}

\section{BALANCED SCORECARD APPLIED TO IN CLINICAL LABORATORY}

Luciano Luz Lopes

Biomédico, Analista Clínico do Laboratório de Análises Clínicas e Ambientais Laboran, Curitiba, PR.

Elenice Stroparo

Farmacêutica-Bioquímica, Doutora em Saúde da Criança e do Adolescente do Setor de Ciências da Saúde da UFPR. Docente do Curso de Biomedicina da Universidade Tuiuti do Paraná.

Kárita Cláudia Freitas-Lidani

Biomédica Microbiologista, Mestre em Medicina Interna e Ciências da Saúde, UFPR. Docente do Curso de Biomedicina da Universidade Tuiuti do Paraná. E-mail: kari.lidani@gmail.com

RESUMO: Este artigo apresenta um modelo de Balanced Scorecard (BSC) proposto para laboratório de análises clínicas, baseado na estratégia de Kaplan e Norton, que apresenta um modelo de gestão em laboratório clínico para empresas de qualquer porte. De acordo com esse modelo, a estratégia é definida em relação a perspectivas financeiras, clientes, processos internos, aprendizado e crescimento. O BSC é um instrumento direcionado para o sistema de gestão estratégica que utiliza indicadores de desempenho baseados em variáveis capazes de interferir direta e indiretamente nas ações da empresa.

Palavras-chave: Balanced Scorecard, Gestão laboratorial, Laboratório clínico

ABSTRACT: This article presents a model of Balanced Scorecard (BSC) proposed for clinical laboratory, based on Kaplan and Norton strategy, which presents a management model for the clinical laboratory business of any size. According to this model, strategy is defined as financial prospects, customers, internal processes, learning and growth. The BSC is an instrument directed to the strategic management system that uses performance indicators based on variables that can affect directly and indirectly in company stock.

Keywords: Balanced Scorecard, Laboratory management, Clinical laboratory 


\section{INTRODUÇÃO}

O cenário empresarial encontra-se cada vez mais competitivo, com tecnologias modernas e avançadas. O setor de Análises Clínicas é um dos ramos que está em constante avanço científico e tecnológico. Diante desta situação observa-se que os profissionais da área da saúde; específico os da área laboratorial, buscam aprimoramento profissional técnico-científico, deixando a formação gerencial para segundo plano, o que sugere uma carência de profissionais qualificados que atuem nesse segmento.

Praticar o gerenciamento ou gestão para acompanhar, avaliar ou medir o crescimento constante da organização é importante pelo fato de diferentes variáveis estarem em constante mudança (impostos, leis, avanços tecnológicos entre outros), o que torna um desafio para muitos profissionais da área laboratorial realizar este tipo de função, abrindo espaço a inserção para profissionais da área administrativa no ambiente de análises clínicas.

Os cursos universitários, na área da saúde, apresentam deficiência por oferecerem pouca ou nenhuma base em administração, apresentando aos discentes a visão técnica e deixando para trás as discussões das operações administrativas que acabam influenciando o bom desempenho e desenvolvimento de uma organização.

Kaplan e Norton (1997) afirmam que "os executivos, assim como os pilotos, precisam de indicadores sobre vários aspectos do ambiente e desempenho organizacional, sem 0 que não teriam como manter o rumo da excelência empresarial".

Para atender as exigências do mercado, torna-se necessário o uso de ferramentas que possam auxiliar o processo gerencial, aplicando técnicas de solução sistemática de problemas, para reduzir ou até eliminar defeitos no sistema como um todo: métodos, produtos e funcionários (Kaplan e Norton, 1997).

Um importante instrumento para o gerenciamento das finanças da empresa é o Balanced Scorecard (BSC), que está dividido em quatro modalidades: 1) Finanças; 2) Processos Internos; 3) Clientes; 4) Aprendizado e Crescimento. Este instrumento de desempenho indica a realidade da empresa, apontando onde a mesma apresenta maior probabilidade para competir, quais os clientes a conquistar, o que é necessário praticar para desenvolver mérito junto aos clientes e acionistas; e, acima de tudo, como identificar e interagir para o crescimento e aprendizado das pessoas que compõem a organização. 


\section{OBJETIVOS}

Nesse sentido, o objetivo do trabalho é demonstrar um modelo proposto de Balanced Scorecard aplicado em laboratório de análises clínicas, a fim de orientar os profissionais da área da saúde para o uso dessa ferramenta como auxílio na gestão laboratorial.

\section{MATERIAL E MÉTODOS}

Este artigo resume-se em três etapas, dentre elas:

- Primeira etapa: compreende uma revisão da literatura que exibe o modelo de estudo proposto. Inicialmente há descrição do módulo de Kaplan \& Norton seguido do modelo de estudo de aplicação do Balance Scorecard ao Laboratório de Análises Clínicas.

- Segunda etapa: expõem alguns pontos como, estrutura organizacional, missão, visão, estratégia, dentre outros que são pertinentes as empresas em geral, com destaque para laboratórios de análises clinicas.

- Terceira etapa: aborda um estudo de cenário empresarial, como modelo, cujos pontos principais são: estrutura do planejamento estratégico, indicadores de desempenho e gerenciamento total, baseado no Balanced Scorecard, os quais dão diretrizes de metodologia para sua implantação.

\section{O Balanced Scorecard (BSC)}

O BSC surgiu pela primeira vez em 1990 como um estudo intitulado de "Mensuring Performance in the organization of the future", patrocinado pela empresa KPMG junto ao instituto Nolan Norton. O trabalho foi realizado por David Norton, executivo principal da Nolan e por Robert Kaplan, como consultor acadêmico (Kaplan e Norton, 1997).

O Balanced Scorecard complementa as medidas financeiras do desempenho passado com medidas dos vetores que impulsionam o desempenho futuro. Os objetivos e medidas do scorecard derivam da visão e estratégia da empresa. Os objetivos e medidas focalizam o desempenho organizacional sob quatro perspectivas: 1) Financeira; 2) Cliente; 3) Processos Internos; e 4) Aprendizagem e crescimento. Essas quatro perspectivas formam a estrutura do Balanced Scorecard, como verificado na Figura 1. 


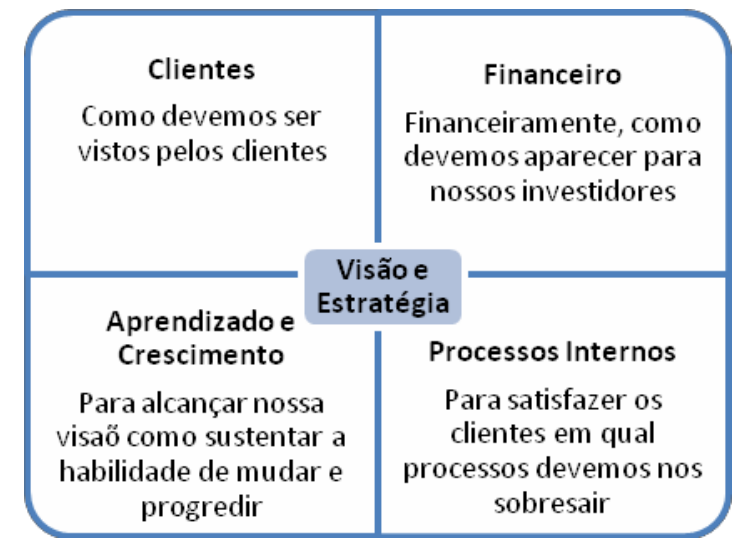

Figura1- Estrutura Balanced Scorecard. Fonte: Kaplan e Norton, 1997.

As medidas financeiras e não financeiras devem fazer parte do sistema da informação para funcionários de todos os níveis da organização. Os funcionários da linha de frente precisam compreender as conseqüências financeiras de suas decisões e ações, os altos executivos precisam reconhecer os vetores de sucesso em longo prazo. As medidas financeiras de desempenho indicam se a estratégia de uma empresa, sua implantação e execução estão contribuindo para a melhoria dos resultados financeiros.

O Balanced Scorecard traduz a missão e a estratégia de uma unidade de negócio em objetivos e medidas tangíveis. As medidas representam o equilíbrio entre indicadores externos voltados para acionistas e clientes, e as medidas internas dos processos críticos de negócios, inovação, aprendizado e crescimento.

O Balanced Scorecard é mais do que um sistema de medidas táticas ou operacionais. Empresas inovadoras estão utilizando o scorecard como um sistema de gestão estratégico para administrar uma estratégia a longo prazo. Elas adotam a filosofia do scorecard para viabilizar processos gerenciais críticos, como apontado na Figura 2.

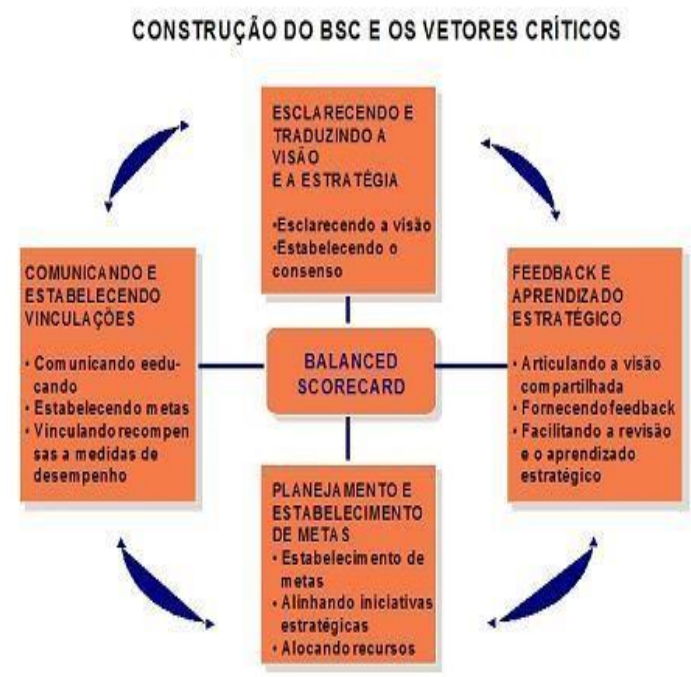


Figura 2- Vetores críticos do Balanced Scorecard. Fonte: Kaplan e Norton, 1997.

$\mathrm{Na}$ perspectiva do cliente, o Balanced Scorecard permite que os executivos identifiquem os segmentos de clientes e mercado nos quais a unidade de negócios competirá e as medidas do desempenho da unidade nesses segmentos alvos.

Na perspectiva dos processos internos, os executivos identificam os pontos críticos da empresa para que a mesma alcance a excelência, direcionados para os parâmetros de maior impacto para a satisfação do cliente, assim como para a consecução dos objetivos financeiros da empresa.

O aprendizado e crescimento organizacionais provêm de três fontes principais: pessoas, sistemas e procedimentos organizacionais. As empresas terão de investir na reciclagem de funcionários, no aperfeiçoamento da tecnologia da informação e dos sistemas, e no alinhamento dos procedimentos e rotinas organizacionais. Assim como na perspectiva dos clientes, medidas baseadas nos funcionários incluem uma combinação de medidas genéricas de resultados - satisfação, retenção, treinamento e habilidades dos funcionários. O scorecard inclui medidas dos resultados desejados e dos processos capazes de assegurar a obtenção desses resultados desejados no futuro.

O Balanced Scorecard traduz missão e estratégia em objetivos e medidas, organizados segundo quadro de perspectivas diferentes conforme mostrado anteriormente. O scorecard cria uma estrutura, uma linguagem, para comunicar a missão e a estratégia, e utiliza indicadores para informar os funcionários sobre os vetores do sucesso atual e futuro. Ao articularem os resultados desejados pela empresa com os vetores desses resultados, os executivos esperam canalizar as energias, as habilidades e os conhecimentos específicos das pessoas na empresa inteira, para alcançar as metas de longo prazo (Kaplan e Norton, 1997).

\section{Modelo Proposto de Balanced Scorecard aplicado em Laboratório de Análises Clínicas}

A estrutura organizacional deve ser delineada de acordo com os objetivos e as estratégias estabelecidas, ou seja, a estrutura organizacional é uma ferramenta básica para alcançar as situações almejadas pela empresa, é o instrumento básico para a concretização do processo organizacional. 
A missão de uma organização significa a razão de sua existência. É a finalidade ou o motivo pelo qual a organização foi criada e para o que ela deve servir. A definição da missão organizacional deve responder a três perguntas básicas: Quem somos nós? O que fazemos? E por que fazemos o que fazemos? Fica evidente que a missão envolve os objetivos essenciais do negócio e está geralmente focalizada fora da empresa, ou seja, no atendimento a demandas da sociedade, do mercado ou do cliente. Interno e Externo (Chiavenato, 1999).

A visão é a imagem que a organização tem a respeito de si mesma e do seu futuro é 0 ato de ver a si própria no espaço e no tempo. Toda organização deve ter uma visão adequada de si mesma, dos recursos de que dispõem, do tipo de relacionamento que deseja manter com seus clientes e mercados, do que quer fazer para satisfazer continuamente as necessidades e preferências dos clientes, de como irá atingir os objetivos organizacionais, das oportunidades e desafios que deve enfrentar, de seus principais agentes, das forças que impelem e das condições em que operam, (Chiavenato, 1999). Dentro das organizações é importante que a missão e a visão sejam bem claras e estabelecidas para toda a equipe que incorpora seu quadro funcional. A Figura 3 apresenta um Modelo de estrutura organizacional .

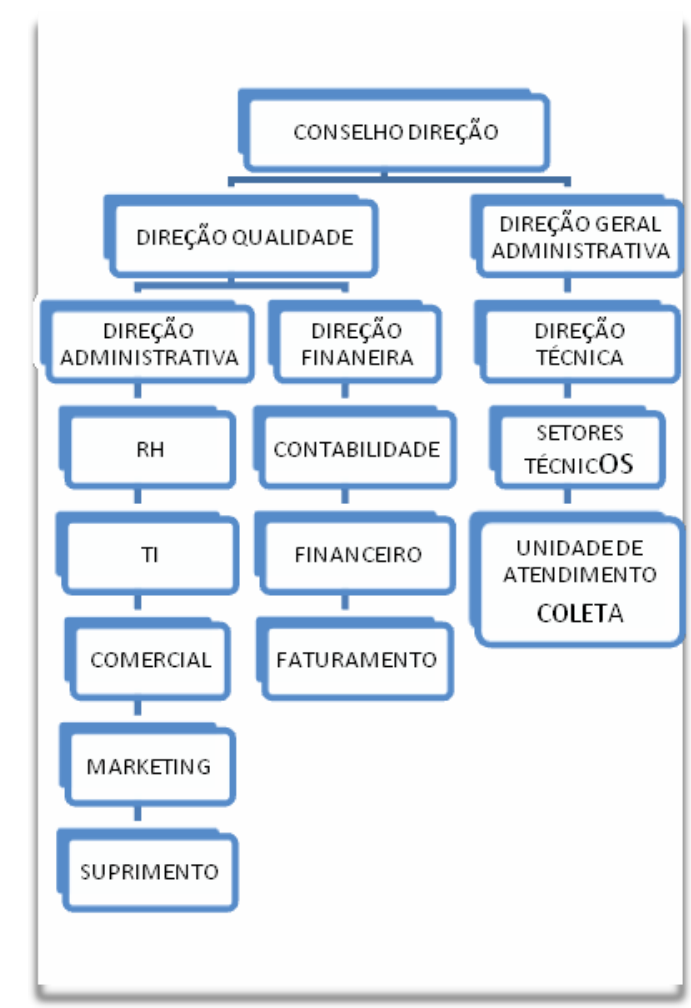


Figura 3- Organograma: Modelo proposto de estrutura laboratorial. RH: Recursos Humanos, TI: Tecnologia da Informação. Fonte: autor do artigo, 2010.

Medir é importante: "O que não é medido não é gerenciado". O sistema de indicadores afeta fortemente o comportamento das pessoas dentro e fora da empresa. Se quiserem sobreviver e prosperar na era da informação, as empresas devem utilizar sistemas de gestão e medição de desempenho derivados de suas estratégias e capacidades. Infelizmente, muitas empresas defendem estratégias baseadas no relacionamento com clientes, competências essenciais e capacidades organizacionais, enquanto motivam e medem o desempenho apenas com medidas financeiras (Kaplan e Norton, 1997).

Segundo Ogushi e Alves (1998) "Num laboratório clínico, comumente, os preços dos serviços prestados são limitados por tabelas de instituições extra laboratoriais ou pela concorrência inter laboratorial. Acrescente-se, além disso, que a funcionalidade desses estabelecimentos defronta com outros obstáculos de difícil transposição e com implicações diretas no campo organizacional-financeiro, entre os quais citamos: exigências da legislação, alto valor financeiro do investimento tecnológico, necessidade de recursos humanos especializados, obrigatoriedade da qualidade total e incertezas do sistema nacional de saúde. Com isso, independente de sua natureza, seja ela estatal ou particular, intra ou extra- hospitalar, dever-se-á dar ao laboratório clínico um tratamento empresarial, dotando-o de objetivos planejados que the proporcionem a eficiência máxima e assim concedendo credibilidade técnica junto à comunidade médica e mantendo ativo o seu potencial econômico-financeiro".

As empresas em crescimento encontram-se nos estágios iniciais de seu ciclo de vida. Possuem produtos e serviços com significativo potencial de crescimento. Para aproveitar esse potencial, talvez tenham que comprometer recursos consideráveis, a fim de desenvolver e aperfeiçoar novos produtos e serviços, construir e ampliar instalações de produção; gerar capacidades operacionais; investir em sistemas, infra-estrutura e redes de distribuição que sustentem relações globais; e alimentar e desenvolver o relacionamento com os clientes. As empresas que se encontram nessa fase podem até operar com fluxos de caixa negativos e baixas taxas de retorno sobre o capital investido (conforme os investimentos sejam interpretados como despesas com ativos intangíveis ou capitalizados para fins internos). Os investimentos feitos para o futuro podem consumir mais recursos 
financeiros do que os gerados atualmente por uma base limitada de produtos, serviços e clientes. O objetivo financeiro global para as empresas na fase de crescimento serão os percentuais de crescimento da receita e de aumento de vendas para determinados mercados, grupos de clientes e regiões (Kaplan e Norton, 1997).

A gestão laboratorial acima de tudo deve estar alinhada com a qualidade total.

Para Motta V. T, Corrêa J. A e Motta L. R, 2001 "O serviço prestado pelo laboratório clínico é uma atividade complexa, influenciada por vários fatores internos e ambientais que podem comprometer seus resultados. A complexidade da prestação de serviços médicolaboratoriais evidencia a necessidade de os laboratórios clínicos repensarem suas estruturas, seus processos e também suas relações de trabalho, pois seus serviços estão profundamente comprometidos com a qualidade dos resultados".

As empresas na fase de crescimento normalmente enfatizam ampliação das linhas de produto existentes ou a oferta de produtos e serviços inteiramente novos. Uma medida comum para esse objetivo é o percentual de receita gerado por novos produtos e serviços lançados dentro de um determinado período, estimado em dois ou três anos. Essa medida tem sido amplamente utilizada por empresas inovadoras, como a Hewlett-Packard (HP) e a 3M Corporation. É claro que, como qualquer boa medida, esse objetivo pode ser alcançado em maior ou menor grau. É preferível que o novo produto ou a extensão de um produto antigo represente uma melhoria radical das opções atuais, que capturem novos clientes e mercados, e não se limitem a substituir as vendas dos produtos existentes. Se houver atenção exagerada a essa medida (um perigo que o Balanced scorecard costuma evitar) (Kaplan e Norton, 1997).

Estendendo essa idéia, as empresas podem optar por aumentar a receita mudando o mix de produtos e serviços. Por exemplo, uma empresa poderia identificar uma substancial vantagem de custo em segmentos selecionados, onde pode derrotar os concorrentes oferecendo preços significativamente mais baixos. Seguindo essa estratégia de baixo custo, ela deverá medir o aumento das vendas nos segmentos alvos. Por outro lado, uma empresa poderia optar por uma estratégia mais diferenciada, dando menos ênfase ás alternativas de baixo custo e deslocando seu mix de produtos e serviços para ofertas com preços mais elevados. Essa empresa optaria por medir o aumento das vendas e 0 percentual das vendas totais no segmento sofisticado (Kaplan e Norton, 1997).

De acordo com Oliva e Borba, (2004) [...] "estratégia é a arte e a técnica de aplicar os 
meios disponíveis com vista à obtenção de objetivos específicos, ou seja, de explorar condições favoráveis com o fim específico de alcançar objetivos".

O Sistema da qualidade também faz parte do processo do BSC onde é fundamental sua atuação. Conforme Santos (2008), "A implantação de um sistema de gestão de qualidade deve ser acompanhada pela alta direção do sistema, através de uma política da qualidade com intenções e diretrizes globais dos laboratórios bem definidas e fortemente expressas e acessíveis ao conhecimento público.

A abordagem administrativa mais recente é o compromisso com a qualidade, definida como a capacidade de atender, durante todo o tempo, às necessidades do cliente; o que significa adequação entre as características do produto ou serviço junto às expectativas do cliente ou consumidor. Mais do que isso, algumas organizações mais bem-sucedidas não se contentam em atender simplesmente às expectativas do consumidor, mas querem ultrapassá- las e encantar os clientes. Para elas, a qualidade é o grau de excelência daquilo que se faz. A qualidade não se faz somente com tecnologia. Ela se faz com pessoas, sobretudo com pessoas capacitadas, treinadas, lideradas, motivadas e plenamente consciente de suas responsabilidades. Qualidade se faz com a participação e empowerment das pessoas. Nesse sentido, a qualidade é, sobretudo, um estado de espírito que reina dentro da organização. Ela exige o comprometimento das pessoas com a excelência (Chiavenato, 1999).

Os administradores devem desenvolver objetivos organizacionais específicos. Objetivos específicos indicam exatamente o que é para ser realizado, quem deve realizá-lo e dentro de que intervalo de tempo. Ser específico elimina confusão acerca dos objetivos e garante que todos os membros da organização conheçam e entendam o que se espera deles. Além disso, a etapa no processo de administração estratégica que segue ao estabelecimento da diretriz organizacional trata da formulação da estratégia organizacional (Certo e Peter, 1993).

No aprendizado e crescimento o Balanced Scorecard enfatiza a importância de investir no futuro, e não apenas em áreas tradicionais de investimento, como novos equipamentos e pesquisa e desenvolvimento de novos produtos. É óbvio que os investimentos em equipamentos são importantes, mas dificilmente serão suficientes por si sós. As empresas devem investir também na infra-estrutura - pessoal, sistemas e procedimentos - se quiserem alcançar objetivos ambiciosos de crescimento financeiro a 
longo prazo. A experiência na elaboração de Balanced Scorecard para uma grande variedade de empresas de serviço e do setor industrial revelou três categorias principais para a perspectiva de aprendizado e crescimento: Capacidade dos funcionários; Capacidades dos sistemas de informação; Motivação, empowerment e alinhamento (Kaplan e Norton, 1997).

\section{Estrutura de Planejamento.}

As formas de $\mathrm{TI}$ (Tecnologia da Informação) avançadas têm conseqüências organizacionais mais amplas e profundas do que as anteriores. Quanto maior a funcionalidade de um sistema de $\mathrm{Tl}$, maiores níveis de aprendizado e ajustamento são necessários para sua utilização, indo desde as habilidades dos operadores por meio dos procedimentos e estrutura organizacionais até os aspectos culturais. Há crescente evidência de que a progressiva utilização e integração de TI aumentam o potencial para automações adicionais, o nível de aprendizado envolvido, o volume de tempo necessário para assimilar a mudança e a necessidade de que o desenvolvimento tecnológico seja guiado por uma estrutura estratégica (Walton, 1998).

A TI em uma organização deve estar alinhada em toda a dimensão de seu quadro funcional para que os processos e informações sejam entendidos e executados com uma abrangência e entendimento totalizada dos processos.

O RH (Recursos Humanos) é outro setor que deve estar alinhado com a estrutura organizacional para que traga bons resultados atuais e futuro da organização. Conforme Motta

V. T, Corrêa J. A e Motta L. R, (2001) referem-se aos recursos humanos como "... imprescindível para a qualidade que os funcionários do laboratório apresentem escolaridade compatível, formação técnica e teórica para os setores específicos. Fundamental, também, é a existência de um programa de educação continuada, disponível para todos os níveis, assegurando, assim, a habilidade e competência, além de promover 0 desenvolvimento técnico intelectual dos colaboradores. A direção do laboratório deve ter um plano organizacional, política de descrição de cargos de pessoal, definindo as suas qualificações e os seus objetivos e deveres."

O marketing das organizações compõe uma estrutura fundamental para 0 
alinhamento não só da demanda clientes, médicos e parceiros como a concorrência externa.

Conforme Pinto (2004) "A concorrência global e as demandas dos clientes, dos cidadãos e do próprio ambiente, estão induzindo a mudança por todas as organizações".

Para acompanhar toda essa complexidade e rapidez com que muito desses fatores estão mudando, é preciso criar sistemas capazes de atender a necessidade de velocidade, de multidimensionalidade, de flexibilidade, de criatividade e de soluções mais simples.

É preciso trabalhar com mais questões e enfrentar vários concorrentes ao mesmo tempo e se relacionar eficazmente com todos eles, identificar as questões chave e enfrentá-las mais rapidamente, integrando o aprendizado por toda a organização para aplicá-lo de forma criativa e flexível.

Podemos então perguntar: $O$ volume de mudanças ocorridas é capaz de manter a posição competitiva? E as mudanças das necessidades dos clientes?

Nos dias de hoje, ainda existem empresas fortalecendo sua área de marketing, concedendo verbas exorbitantes para o lançamento e divulgação de seus produtos e serviços, preocupados apenas com a concorrência e seu faturamento, deixando o principal objetivo mundial, "encantar o cliente" [...]

"Um hospital ou um laboratório de análises clínicas, para poder atender bem, precisa que seu quadro de funcionários esteja motivado e comprometido com o pocesso de qualidade" Cobra (2001)

“As organizações já notaram a necessidade de alterar seus modelos de gestão baseados no desempenho individual para um novo paradigma: o trabalho em time. A busca dessa nova realidade organizacional tem como objetivos aumentar a produtividade, a competitividade e a eficiência”. Casado (2002).

\section{CONCLUSÃO}

É possível observar a importância de profissionais da área laboratorial aos sistemas administrativos, com maior interação na área de gestão como um todo.

No mercado competitivo atual e como perspectiva futura em análises clínicas, fica clara a necessidade de profissionais não só com a visão técnica e científica, mas com a 
visão global e administrativa.

O gestor de um laboratório Clínico além de estar na linha de frente deve ter conhecimentos e preparação para atrair olhares de acionistas além de obter toda a equipe alinhada para executar cada processo com eficiência, com objetivo de buscar no mercado interno e externo a qualidade total, satisfação interna e externa com sucesso.

Contudo o Balanced scorecard apresenta ferramentas capazes de alinhar e ajustar cada processo individualmente podendo interagir direta ou indiretamente dentro da organização seja ela de qualquer porte.

\section{REFERÊNCIAS BIBLIOGRÁFICAS}

CASADO, T. A motivação e o trabalho, in: Fleury, M. T. L. (org). As pessoas nas organizações (2 ed.). São Paulo: Gente, 2002.

CERTO, S. C.; PETER J. P. Administração Estratégica: planejamento e implantação da estratégia. Makron Books, São Paulo, 1993.

CHIAVENATO, I. Administração nos novos tempos. Rio de Janeiro: Campus, 1999.

COBRA, M. Estratégias de marketing de serviços. São Paulo: Cobra, 2001.

KAPLAN, R. S., NORTON, D. P, Estratégia em ação. Rio de Janeiro: Campus, 1997.

MOTTA, V. T.; CORRÊA, J. A.; MOTTA, L. R. Gestão da Qualidade no Laboratório Clínico. Porto Alegre: Médica Missau, 2001.

OGUSHI, Q.; ALVES, S. L. Administração em Laboratórios Clínicos: gestão da qualidade, estrutura operacional e componentes financeiros. São Paulo: Atheneu, 1998.

OLIVA, F. A.; BORBA, V. R. BSC - Balanced Scorecard - Ferramenta gerencial para organização hospitalares. São Paulo: látria, 2004. 
PINTO, S. C. Marketing de serviço. 0 incentivo a produtividade nas empresas. Rio de Janeiro, 2004.

SANTOS, E. G. O. B.; PEREIRA, M. P. L. e SILVA, V. L. Gestão da qualidade nos Laboratórios Centrais de Saúde Pública e o modelo de controle de qualidade analítica de malária. Epidemiol. Serv. Saúde. Brasília, 17(2):117-122, 2008.

WALTON, R. E. Tecnologia da informação. O uso de TI pelas empresas que obtêm vantagem competitiva. São Paulo, Atlas, 1998. 